\title{
Path and Effectiveness Evaluation of Language Poverty Alleviation - Based on the Practice in Poor Areas
}

\author{
Zehai Liu ${ }^{1, *}$ \\ ${ }^{1}$ College of International Education, Jishou University, Jishou, Hunan 416000, China \\ *Corresponding author. Email: JSSZ8512474@163.com
}

\begin{abstract}
Poverty is a common topic facing mankind. Targeted poverty alleviation with language is an important part of poverty alleviation, and language can play a bigger role in the targeted poverty alleviation strategy. In China, promotion of Putonghua is conducive to poverty reduction and poverty alleviation because of the relationship between language and education. This paper reviews the main course of the cause of language poverty alleviation in the People's Republic of China, explains the main path of language poverty alleviation through cases, analyzes the role of language in poverty alleviation, and explains the effect evaluation of language poverty alleviation.
\end{abstract}

Keywords: poverty-stricken areas, language poverty alleviation, path, effectiveness evaluation

\section{INTRODUCTION}

Poverty alleviation and reduction is a historic and worldwide challenge. It is also a goal pursued by responsible countries all over the world. In November 2016, the State Council of China issued the Plan for Poverty Reduction during the 13th Five-Year Plan Period, which aims to lift China's rural poor out of poverty by 2020 , lift all povertystricken counties out of poverty, and solve the regional poverty problem as a whole. It has been proved that there is a correlation between language and poverty, and language can help poverty alleviation, which stems from the close relationship between language and education. To carry out language poverty alleviation and make language play a real role in poverty alleviation, it is necessary to study the theoretical relationship between language and poverty, and summarize and draw lessons from domestic and foreign approaches and practical experience of language poverty alleviation. China's language poverty reduction is actually to solve the problem of poverty at two levels. The first is to solve the problem of large-

*Projects: This paper is the research results of Hunan Social Science Achievement Evaluation Committee (XSP19YBC080) in 2019, Hunan Provincial Education Department Research Project (18C0582), Hunan Provincial Higher Education Research Project of Curriculum ideological and political Construction (HNKCSZ-2020-0353) in 2020, Hunan Provincial Degree and Graduate Education Reform Project (2020JGYB215) in 2020, and Research Projects of Jishou University (JDZDZB072 \& 2020KCSZA12) in 2018 and 2020. scale poverty, that is, regional poverty (especially the 14 contiguous poverty-stricken areas). One way is to promote Putonghua, the second is to promote the value of local languages (including ethnic languages and Chinese dialects); Second, to solve individual and family poverty, which requires targeted poverty alleviation, not only to improve the language ability, but also to pay attention to the application of language technology; The third is to pay attention to the language life of the displaced people in the inhospitable areas to promote the construction of a harmonious language life. By 2020, China's rural poor have achieved the goal of overall poverty alleviation. The next goal is to prevent the people who have been lifted out of poverty from returning to poverty, so it is necessary to evaluate the effectiveness of language poverty alleviation.

\section{LITERATURE REVIEW}

\section{A. Analysis of domestic literature}

The special research on language and poverty or poverty alleviation is in the ascence, and there are few relevant works. Scholars at home and abroad have made theoretical and empirical research on language and poverty from the following topics: policies and measures for language poverty alleviation, the relationship between economic development and language diversity, the mental, linguistic and cognitive retardation of individuals in 
poor environments, and the language development of poor children. In recent years, the special research on language and poverty focuses on the following aspects: First, the research on the important value of Putonghua in targeted poverty alleviation. Li Yuming (2018) believes that poverty alleviation needs to be supported by building a language road. Helin (2018) believes that language poverty alleviation is conducive to permanent poverty alleviation. Bian Chenglin (2017) believes that "targeted poverty alleviation through language" is the premise and guarantee for the implementation of the national targeted poverty alleviation strategy. The second is the research on the effect and countermeasures of targeted language poverty alleviation. It mainly includes research on how language plays a role in poverty alleviation. $\mathrm{Li}$ Lingfeng (2018) believes that ethnic minority areas should strengthen the Chinese language ability of the poor population to alleviate poverty, so as to provide a solid guarantee of language ability and endogenous power for long-term poverty alleviation. Shi Lin (2018) proposes the strategy of deepening the promotion of national language in ethnic minority areas from the perspective of targeted poverty alleviation. The third is the multidisciplinary study of language and poverty (poverty alleviation). Wang Jiayi (2016) studies the relationship between education and targeted poverty alleviation from the perspective of pedagogy. Fang Qingyun (2012) studies the strategic choice of poverty alleviation in western Hunan from the perspective of cultural poverty alleviation; $\mathrm{Wu}$ Xiongzhou and Ding Jianjun (2015) studies targeted poverty alleviation from the perspective of economics by taking poverty alleviation in Shibadong Village, Xiangxi Autonomous Prefecture as an example, and found that there was a evolution from single-dimensional targeting to multi-dimensional targeting. In terms of language and poverty theory, Wang Hailan (2019) believes that the promotion of national language can reduce the negative impact of language diversity, as an individual's Putonghua level, foreign language ability and dialect skills affect his or her labor income. There is a strong link between language skills and an individual's and a country's economic status. As Wang Chunhui (2019) said, "Language competence is a probabilistic condition for the promotion of economic and social status." $\mathrm{Li}$ Yuming (2019) believes that language can help poverty alleviation because language is closely related to education, information and human capital. With the advancement of poverty alleviation work, the influence of language on economy is gradually highlighted. The unified promotion of Putonghua, the improvement of language ability, and the importance of the basic status of language factors are an important language policy to promote economic and social development, assist in the battle of poverty alleviation, and realize the "true" poverty alleviation. As for the impact of economy on language, in the theoretical exploration of language poverty alleviation, some scholars have demonstrated the scientific nature of language poverty alleviation. Wang Chunhui (2019) believes that people in poor areas are limited to the current environmental state due to the lack of language ability, which inhibits the possibility of development. Wang Haoyu (2019) demonstrates the interactive relationship between language and economy in an empirical study on the language competence and social and economic status of the minority youth in Tianzhu County, Gansu Province.

Some scholars have done a study on language poverty alleviation in relocation work. When some poor people move away from their original place of residence, the language environment will change accordingly. The existing research concerns the language and cultural adaptation of the migrants, the development of language skills and the harmony between the original language and the new language. It is an inevitable problem for residents to adapt to the language and culture of the new environment, especially for the middle-aged and elderly people who are hindered by their own language and learning ability. Tian Guanghui, Tian Zefeng et al. (2018) point out that special Putonghua learning base should be established for this group. Tian Guanghui and Yang Gengmei (2019) believe that language use in immigrant communities should be investigated, the relationship between languages in communities and their development rules should be analyzed, the corresponding evaluation system should be established, and the promotion of Putonghua should be combined with the effective protection and development of various languages and cultures in communities. The two-way dialectical development of promoting Putonghua and protecting language harmony is an important guarantee for residents to truly enjoy the "language dividend", to tap the resource potential of language and turn it into human capital, and to win the battle of poverty alleviation an indispensable force in the world.

\section{B. Analysis of foreign literature}

This research has accumulated a rich literature. One is the study on the definition of poverty. There are a lot of researches in this field, but few have incorporated "language" elements into the connotation of "poverty". The 1990 Human Development Report of the United Nations Development Programme (UNDP) identified literacy as an important indicator of poverty. Life expectancy, literacy and living standards of poverty can be measured using the Human Poverty Index. The other is the study on the relationship between 
language and poverty. There has been some attention to this research. Proceedings of Williams (Williams, 1970), editor of Language and Poverty: a Variety of Perspectives on the Same Topic and Harbert (Harbert et al. 2008) editing and publication of the language and the poor from different perspectives discussed the poverty and language skills, language status, the relationship between language rights, as well as the social resources for poverty, language diversity and the influence of language policy. In 1966, Fishman observed that all wealthier countries had a relatively uniform language, or "homogeneity"; poorer countries, on the other hand, have greater linguistic diversity, that is, have "heterogeneity". In 1972, based on Fechmann's research, Pool analyzed the correlation between per capita GDP and language status of 133 countries around 1962, and found that "a country with extremely complex language is always underdeveloped or semideveloped; and a highly developed country always has a high degree of linguistic unity ". This is the Fichman-Poole hypothesis of the correlation between language and poverty. It is somewhat universal. The third is the research on the economic value of language. According to Swiss economist Green, "a country's multilingual ability helps create more economic value." Chinese scholars have studied the relationship between migrant workers' Putonghua ability and salary income, proving that language ability, especially lingua franca ability and multilingual ability are positively correlated with salary income. This shows from the side that it is very important and urgent to actively promote mandarin in ethnic minority areas and carry out targeted language poverty alleviation. At the same time, the research achievements on language and poverty include the following hot spots: language and living poverty (Groff 2018), language and values, ability poverty (Laitin 2016), social monolingual to social bilingualism (Durk 2017), and measurement of language poverty (Hult 2018). Language poverty causes a series of poverty and is the source of poverty.

To sum up, the existing research has been limited to the abstract and macro issues of language and poverty comparison. The targeted poverty alleviation effect and improvement path of the poverty-stricken areas are still to be further studied, especially the difficulties and main countermeasures in the process of promoting the real poverty alleviation of the poverty-stricken people in poverty-stricken areas.

\section{THE MAIN COURSE OF POVERTY ALleViation IN THE PEOPLE'S REPUbliC OF CHINA}

Over the past 70 years since the founding of the People's Republic of China, it has made remarkable achievements in poverty alleviation. As an integral part of poverty alleviation, language poverty alleviation has achieved remarkable results. China's adult literacy rate rose from about 65 percent in 1982 to 96.4 percent in 2015; and the Putonghua popularizing rate rose from 53 percent in 2000 to 73 percent in 2015 .

From the beginning of the founding of the People's Republic of China to the present day, the major tasks of language work include the simplification of Chinese characters, the promotion of Putonghua, the implementation of the Hanyu Pinyin Plan, the standardization of Chinese language and so on. Since 1949, the cause of language poverty alleviation has focused on these works as a whole, which has indirectly helped China's poverty alleviation and reduction work silently.

\section{A. Putonghua promotion}

The promotion of Putonghua has long been a central part of China's efforts to alleviate poverty through language use. In 1982, the Constitution of the People's Republic of China incorporated "the promotion of Putonghua as a national standard" into the Constitution, making the promotion of Putonghua a basic state policy. In 1998, with the approval of the State Council, the third week of September was set as "National Putonghua Publicity Week". In 2001, the Law of the People's Republic of China on the Standard and Written Chinese Language came into effect, stipulating that "the standard and written Chinese language is Putonghua and standard Chinese characters", further clarifying the legal status of Putonghua and standard Chinese characters. In addition, education, radio, film and television, tourism and other systems and industries have also issued regulations and documents related to Putonghua.

\section{B. Simplification and standardization of Chinese characters}

On February 5, 1952, the Chinese Character Reform Research Committee was established. In December 1954, the Chinese Characters Reform Committee was established. In 1956, the promulgation and promotion of the Simplification of Chinese Characters started the history of simplifying and standardizing Chinese characters to alleviate poverty. On August 12, 2009, the Ministry of Education just developed the "General Standard Chinese Characters List (Draft for Public Opinion)" to solicit public opinions, and officially 
issued on June 5, 2013. Standardized simplified Chinese characters are one of the most powerful tools to significantly increase the literacy rate and reduce illiteracy rate in China. In this sense, the simplification and standardization of Chinese characters have contributed a lot to the development of education and the cause of poverty alleviation.

\section{Implementing the Chinese Pinyin Scheme}

Although the production process of the Chinese Pinyin Scheme is very difficult, the history of more than 60 years shows that the plan plays a special role in the aspects of phonetic transcription of Chinese characters, helping students learn, serving as the basis for the creation and reform of characters of ethnic minorities, reducing illiteracy rate, and improving the efficiency and effect of education. In 1986, when the state formulated the policy on language and characters in the new era, it clearly pointed out that "the current the Chinese Pinyin Scheme is not a pinyin script to replace Chinese characters, but a phonetic tool to help learn Chinese, Chinese characters and promote Putonghua".

\section{Creation of writing}

Since 1956, the Chinese government on the basis of the national minority language census, in succession to zhuang, dong, li, miao, yi, naxi, lisu, hani, qiang, wa, 13 ethnic minorities such as tu, had created 17 kinds of Latin alphabet writing letters form, reforming and improving the existing dai, miao, jingbo Chinese minority scripts. The newly created and reformed written languages of ethnic minorities have played an important role in eliminating adult illiteracy, developing education for ethnic minorities, training talents of ethnic minorities, and inheriting and developing culture of ethnic minorities.

\section{E. Literacy eradication}

When the People's Republic of China was founded, over 80 percent of the country's 540 million people were illiterate. In rural areas, the illiteracy rate is more than 95 percent. From 1949 to 2010, China's population increased from 540 million to 1.34 billion, but the illiterate population decreased from 432 million in 1949 to 55 million in 2010, thus eliminating 273 million illiterates and reducing the national illiteracy rate from over 80 percent to 4.08 percent. There is no doubt that the above mentioned language work has provided the necessary conditions and academic support for the development of literacy.

\section{F. Norms and standards}

According to the statistics of the Chinese Language Standards and Standards Research Center, there are 47 standards of 6 categories of national standard language for social application. These standards provide a standard for the teaching and use of the national standard language, and also provide a reference for the development of language poverty alleviation.

\section{G. Improving the legal system}

Since the founding of the People's Republic of China, especially since the reform and opening up, China has promulgated a series of laws and regulations on language, and a large number of laws and regulations contain provisions on language issues. According to statistics, there were nearly 2,200 by 2016 , covering constitutions, laws, regulations, rules and normative documents. The legal construction of language and written language provides a legal basis for the service of language and written language in poverty alleviation and national development.

\section{H. Language poverty alleviation in the new stage}

In May 2011, the CPC Central Committee and the State Council issued the Outline of Poverty Allowance and Development in China's Rural Areas (2011-2020), which mentioned the "comprehensive promotion of the national standard language in ethnic minority areas", which was the first time that the measures were expressed in language in the poverty alleviation policies at the national level. In 2012, the CPC Central Committee put forward the important ideas of "Targeted Poverty Alleviation" and "Targeted Poverty Alleviation", marking the beginning of a new journey of poverty alleviation and reduction in China. Since the Outline of Poverty Alleviation and Development in China's Rural Areas (2011-2020), the cause of language poverty alleviation has been directly involved in the overall planning of national poverty alleviation, and has since entered a new stage of direct participation and systematic promotion of the cause of language poverty alleviation in China.

\section{THE MAIN PATH OF LANGUAGE POVERTY ALLEVIATION}

The main ways of language poverty alleviation are to promote the national language and to create a harmonious language life for the migrant communities relocated from inhospitable areas. 


\section{A. Promoting the use of standard Chinese and spoken languages to alleviate poverty}

In the new situation, in order to achieve targeted and precise poverty alleviation in poor areas, language must be taken as the starting point. Through the comprehensive improvement of the language communication ability based on the national standard language, it is believed that the poor people may have the ability to obtain information and strengthen their own levels of human resources and competitiveness, so as to promote the people in poor areas to achieve permanent poverty alleviation.

1) Analysis on the common language proficiency of the poor population in western Hunan and its causes of poverty: The western part of Hunan Province is the area with the largest base of poor population and the most backward level of economic development. Another problem is low levels of education and a poor command of the country's spoken and written language. This makes its economy and culture lack of interaction with the outside economy and culture to a certain extent. Because of the language barrier, it leads to the obstruction of labor mobility, the lack of job opportunities, the low competitiveness, the weak ability to obtain knowledge and information, the backward concept, the lack of self-confidence and self-improvement spirit, the backward degree of high-tech mastery and the narrow space for selfimprovement. Because they cannot master the national language, the labor force in poor areas is often at the lowest end of the market industry chain, and it is difficult for them to integrate into the current market economy society and share the fruits of the rapid economic and social development.

2) Analysis on the poverty alleviation path of national language proficiency in poor areas

a) The implementation of the national standard language of the school is vigorously strengthened: The implementation of the national standard language in schools should start from basic education. First of all, we should continue to increase the investment of education guarantee funds in the stage of basic education to ensure that all school-age children can get the best educational resources. Secondly, the linkage and transformation of teaching mode from "bilingual teaching" to "national standard language teaching" should be promoted in an orderly way. Finally, a strong atmosphere of learning the national language in the basic education stage should be created. It's needed to advocate teachers and students to use the national standard language to communicate in and out of school. b) The language training work system in the rural labor force should be perfected: In order to achieve long-term poverty alleviation, rural labors in poor areas need to take the initiative to learn the national language under the guidance of the local government, so as to broaden their horizon, obtain more information resources, and gradually improve their adaptability and development ability to embark on the road to prosperity. Through carrying out policy propaganda, information dissemination, scientific and technological training and other peasant education activities based on the national language, it is hoped to gradually change the situation that the surplus labor force in poor areas can only use their mother tongue, so that they can gradually adapt to the pace of the development of modern science and technology in the information society.

c) Schools should play the roles of language driving and radiating to the society and family: The language poverty alleviation of the poor also needs to take the lead to the school's role in driving and radiating the language of the society and the family, and extend the language communication from the school to the family and the society. Students are encouraged to insist on speaking the standard Chinese at home and in the community, from school to family and from family to community, to create a good atmosphere for learning the standard Chinese, to take the lead to the basic, driving and radiating role of schools in the language work, and to form the influence of effectively promoting the standard Chinese.

d) The development of common language resources and platforms should be strengthened: To establish the concept of national standard language resources, we should upgrade the standard language resources to an economic resource, pay attention to its development, construction and utilization, promote people's understanding of this theoretical trend, and build a good atmosphere for language learning of national standard language. At the same time, universities will take the lead to establish a learning platform and a national language resource bank to further standardize the use and promotion of the national language.

\section{B. Creating a harmonious language life for the poverty-stricken resettled communities in inhospitable areas}

Language harmony is the basic requirement for the harmonious development of society. There are inevitable language conflicts and competition in the resettlement communities of poverty alleviation in inhospitable areas. It is also one of the tasks of language work and poverty alleviation to solve the 
problem of language harmony in the resettled communities from inhospitable areas.

1) Analysis on the language harmony of migrant communities relocated to alleviate poverty from inhospitable areas: Language is the communication tool of all groups in the povertystricken resettlement communities in Hunan Province. The characters of all groups in the poverty-stricken resettlement communities in Hunan Province are the most important carrier of language, and also the important carrier on which language depends for inheritance and development. Due to historical and other reasons, some groups have their own language but no written language, which greatly restricts the development of language, and seriously restricts and affects the inheritance and development of language and culture of all groups in the resettlement communities of poverty alleviation from inhospitable areas in Hunan Province. The language harmony among different groups in the resettlement community is an essential factor to build a harmonious society. A series of problems need to be solved in order to realize the language harmony among the groups of the poverty-stricken resettlement communities in Hunan inhospitable areas. For example, what are the specific indications of the language harmony in the povertystricken resettlement communities in Hunan inhospitable areas? How to achieve harmonious coexistence between the common language of immigrant community and extraneous language? What other improvements should be made in relevant language planning and language policies to achieve language harmony in immigrant communities? All the above are the manifestations of language harmony in the poverty-alleviation resettlement communities in Hunan province.

2) Path selection to solve the problem of language harmony in poverty-alleviation resettlement communities in Hunan inhospitable areas: To solve the problem of language harmony in the poverty-stricken resettlement communities in Hunan province, firstly, various local laws and regulations concerning language protection and development and the language protection policies of the local government should be sorted out, and the role and effectiveness of the current language protection and development related policies should be evaluated scientifically. Secondly, it is necessary to comprehensively understand the basic situation of the language of the poverty-relief resettlement communities in Hunan Province from the aspects of environment, population and historical evolution, and analyze the relationship between the language and society and culture and the language pattern of the poverty-relief resettlement communities in the inhospitable areas. Finally, the linguistic features of each group in the resettlement communities should be well protected. From the perspective of living type, dynamic, language, culture, etc., we should choose the most representative language points to observe, compare, evaluate and predict language influence caused by language contact, language combination, the phenomenon such as language conversion and language variation, so as to protect language complementary and language development for poverty alleviation immigrant communities of Hunan.

\section{THE ROLE OF LANGUAGE IN POVERTY ALLEVIATION}

Improving Mandarin proficiency in povertystricken areas will help fight poverty. The promotion of Mandarin Chinese plays some important roles: (1) The promotion of Mandarin Chinese is conducive to reducing the uncertainty in communication, promoting the spread of knowledge and technology, forming team cooperation easily, expanding the "learning effect" among entrepreneurs, and promoting innovation and entrepreneurship of migrant workers in cities. (2) A large number of first-hand data, such as the Survey of Chinese Labor Force, prove that the educational level of ethnic minorities is almost the same as that of the Han nationality, and the more important reason that affects the employment and income opportunities of ethnic minorities is the weakness of Putonghua ability. Therefore, one of the prerequisites for improving ethnic equality is the promotion and popularization of Putonghua among ethnic minorities. In order to promote economic and social development in minority areas, Chinese teaching should be strengthened. (3) For the poverty stricken areas in Chinese dialect areas, it is also of fundamental importance to strengthen the promotion of Mandarin and improve the level of local people's Mandarin. Because dialect differences impede labor market mobility, people who speak only dialects tend to have lower economic earnings than those who speak a common language.

\section{EFFECTIVENESS EVALUATION OF LANGUAGE POVERTY ALLEVIATION}

Methods should be paid attention to in the concrete operation of the evaluation of the effect of poverty alleviation through language. From the perspective of evaluation subjects, it is suggested to adopt the third party evaluation and pay attention to the combination of experts and grassroots poverty 
alleviation personnel. From the perspective of the selection of evaluation objects, we should regard urban and rural areas as an organic whole and avoid simply evaluating the effect of poverty alleviation through rural language. From the perspective of content design, attention should be paid to the utilization of language resources. From the evaluation means, attention should be paid to the use of the latest scientific and technological achievements.

\section{A. It is suggested to adopt a third party agency to carry out the evaluation}

Third-party evaluation is widely used in the evaluation of policy effect of public organizations, government performance management and the completion effect of government projects, etc. It has the characteristics of independence, professionalism and authority. It is a major decision of the government to implement a third-party evaluation system in the assessment of the effectiveness of the national targeted poverty alleviation work and the assessment of the withdrawal from poverty. It is a major initiative that benefits the country and the people, and also a major innovation in China's targeted poverty alleviation work.

\section{B. Attention should be paid to the combination of experts and grassroots poverty alleviation personnel}

The evaluation of the effect of poverty alleviation should attach importance to the role of experts as well as grass-roots poverty alleviation personnel, which is the concrete implementation of the principle of combining theory with practice. Experts play a main role in the evaluation, reflecting the theoretical, scientific and integrated nature of the evaluation, while grassroots poverty alleviation personnel have rich practical experience and master the typical cases and the people's attitudes, preferences and other first-hand data that are difficult to be formally expressed. Although it cannot be said that experts are completely ignorant of the actual situation, there are indeed some deficiencies in the aspects of "combining knowledge and action" and "progressing with knowledge and action", especially for indirect factors such as language poverty alleviation that do not directly affect the income of the poor population, the evaluation should be carried out by combining the two factors.

\section{Attention should be paid to the utilization of language resources}

In addition to the promotion of poverty-stricken areas, language poverty alleviation can be organically combined with the development of data industry and tourism industry in poverty-stricken areas. For example, data annotation industries of ethnic minority languages, cross-border languages, and economically valuable dialects, cultural and creative industries based on characteristic language and culture, tourism industries, etc., should include the poverty reduction effect generated by language resources directly helping these service industries into the evaluation of language poverty alleviation effectiveness. In the context of the great achievements made in the national popularization, the future practice of language poverty alleviation will be mainly reflected in these aspects, which is also where language can play a great role in the implementation of rural revitalization strategy, and the focus of the evaluation of the effect of language poverty alleviation will move to this point.

\section{Attention should be paid to the use of the latest scientific and technological achievements}

In terms of data collection and evaluation methods, attention should be paid to the latest scientific and technological achievements of artificial intelligence, big data analysis and social computing, so as to improve the accuracy, validity and efficiency of evaluation. In the planning and implementation of verbal poverty alleviation effectiveness evaluation, attention should be paid to the establishment of open and dynamic evaluation data collection, analysis and display platform. Within the scope permitted by laws and regulations, evaluation data should be opened to scientific research institutions and society in different levels to realize multiple exploitation and utilization of evaluation results.

\section{CONCLUSION}

Language poverty alleviation is a basic and leading measure of poverty reduction. There is no doubt that the ongoing poverty alleviation in contemporary China provides a distinctive background and material for the study of language and poverty. Of course, many questions need to be further studied. For example, the year 2020 was the end of China's struggle against poverty. In the postpoverty era, what are the paths and modes of language poverty alleviation and poverty reduction, and how to apply language technology in language poverty reduction, are all questions worth thinking about. Poverty alleviation through language means is a long-term task. After the overall regional poverty problem had been resolved by 2020 , it is still necessary to promote poverty alleviation among special groups, families and local governments. Moreover, the fight against poverty is a topic of common concern for all mankind. China's promotion of poverty alleviation can also be used as a reference for global poverty reduction and contribute Chinese wisdom to the cause of poverty reduction of mankind. We look forward to more 
scholars joining the research team on language and poverty, and more importantly, we look forward to contributing to the cause of poverty reduction in China and the human race.

\section{References}

[1] Chiswick B R, Patrinos H A, Hurst M A. 2000. Indigenous Language Skills and the Labor Market in a Developing Country: Bolivia [J]. Economic Development and Cultural Change 48(6), 349-367.

[2] Harbet, W., M. Sally \& M. Amanda. 2008. Language and Poverty [M]. Cleveton: Multilingual Matters.

[3] Igboanusi Herbert. 2014.The Role of Language Policy in Poverty Alleviation in West Africa [J]. International Journal of the Sociology of Language 25(5), 75-90.

[4] Justice, L. M., H. Jiang, K. M. Purtell, et al. 2019. Conditions of poverty, parent-child interactions, and toddlers' early language skills in low-income families [J]. Maternal and Child Health Journal 23(7), 971-978.

[5] McCoy, D. C., C. Salhi, H. Yoshikawa, et al. 2018. Homeand center-based learning opportunities for preschoolers in low-and middle-income countries [J]. Children and Youth Services Review 88(6), 44-56.

[6] Williams, F. 1970. Language and Poverty: Perspectives on a Theme [M]. New York: Academic Press. 